\title{
Inhibitory effect of esculetin on migration, invasion and matrix metalloproteinase-9 expression in TNF- $\alpha$-induced vascular smooth muscle cells
}

\author{
SE-JUNG LEE ${ }^{1,3}$, UNG-SOO LEE ${ }^{1}$, WUN-JAE KIM ${ }^{2}$ and SUNG-KWON MOON ${ }^{1}$ \\ ${ }^{1}$ Department of Food and Biotechnology, Chungju National University, Chungju, Chungbuk 380-702; \\ ${ }^{2}$ Department of Urology, Chungbuk National University College of Medicine, Cheongju, Chungbuk 361-763; \\ ${ }^{3}$ Department of Food Science and Technology, Chung-Ang University, Ansung 72-1, Korea
}

Received October 5, 2010; Accepted December 30, 2010

DOI: $10.3892 / \mathrm{mmr} .2011 .420$

\begin{abstract}
Esculetin, a potent non-competitive inhibitor of lipoxygenase, has been shown to inhibit vascular smooth muscle cell (VSMC) proliferation. However, the effect of esculetin on the matrix metalloproteinase-9 (MMP-9) regulation responsible for cell migration and invasion has not been previously investigated. The results of the present study showed the esculetin $(12.5-25 \mu \mathrm{g} / \mathrm{ml})$ induced the inhibition of migration and invasion in tumor necrosis factor- $\alpha$ (TNF- $\alpha$ )treated VSMC, as demonstrated by a matrigel invasion assay and wound healing analysis. However, esculetin did not affect cell viability in TNF- $\alpha$-treated VSMC under $0-25 \mu \mathrm{g} / \mathrm{ml}$ concentration conditions. In addition, both zymographic and immunoblot experiments showed that esculetin suppressed the TNF- $\alpha$-induced expression of MMP-9 in VSMC in a dose-dependent manner. Furthermore, the treatment of cells with esculetin decreased the activity of the TNF- $\alpha$-induced MMP-9 promoter, which was driven by a luciferase reporter. Finally, esculetin reduced the binding activities of nuclear factor- $\kappa \mathrm{B}(\mathrm{NF}-\mathrm{\kappa B})$ and activator protein-1 (AP-1), which are cis-elements present in the promoter of the MMP-9 gene, in TNF- $\alpha$-treated VSMC. Taken together, these results demonstrated that esculetin decreased the migration and invasion of cells by suppressing MMP-9 expression, which subsequently reduced the binding activities of NF- $\mathrm{\kappa B}$ and AP-1 in TNF- $\alpha-$ treated VSMC. These novel findings provide basic information for effective therapeutic treatment with esculetin for atherosclerotic disease.
\end{abstract}

Correspondence to: Dr Sung-Kwon Moon, Department of Food and Biotechnology, Chungju National University, 123 Geomdan-ri Iryu-myeon, Chungju, Chungbuk 380-702, Korea

E-mail: sumoon66@dreamwiz.com

Key words: esculetin, vascular smooth muscle cell, tumor necrosis factor- $\alpha$, matrix metalloproteinase- 9 , nuclear factor- $\kappa \mathrm{B}$, activator protein-1, migration, invasion

\section{Introduction}

The growth of arterial lesions, such as vascular remodeling, is a critical step in the pathogenesis of atherosclerosis and restenosis after balloon angioplasty $(1,2)$. The proliferation and migration of vascular smooth muscle cells (VSMC) from the media toward the intima are involved in vascular remodeling in response to injury $(1,2)$. VSMC migration requires the degradation of extracellular matrix (ECM) proteins, which is regulated by matrix metalloproteinases (MMPs) $(2,3)$. Studies on the role of MMPs in the basement degradation of VSMC (3) have focused on the gelatinases MMP-2 $(72 \mathrm{kDa})$ and MMP-9 (92 kDa). The expression of MMP-2 and MMP-9 was increased in balloon injury models, which resulted in vascular lesion formation (4). Previous studies have suggested that MMP-9 plays a pluripotent role in the growth of neointimal lesions in atherosclerosis (5-8). For instance, MMP-9 showed low expression in normal arteries, but was up-regulated in rat carotid arteries $6 \mathrm{~h}$ after injury, and this condition continued for 6 days (6). Accumulated data have emphasized that the loss of MMP-9 indicates significantly retarded arterial lesion growth through the control of VSMC migration in MMP-9-/ animals $(7,8)$. As a result, a great deal of effort is being directed toward the development of therapies that inhibit VSMC migration to prevent atherosclerosis or restenosis (9).

The formation of vascular lesions occurs during several critical pathological processes, which are associated with the accumulation of inflammatory cells and the secretion of cytokines (10). The presence of cytokine tumor necrosis factor- $\alpha$ (TNF- $\alpha$ ) has been found in VSMC after balloon injury (11). In addition, previous studies demonstrated TNF- $\alpha$ expression in intimal VSMC and in atherosclerotic plaques $(12,13)$. Cumulative data have demonstrated that MMP-9 is activated by TNF- $\alpha$ in VSMC $(14,15)$. Additional studies identified the essential proximal activator protein-1 (AP-1) and nuclear factor- $\kappa \mathrm{B}(\mathrm{NF}-\mathrm{\kappa B})$ binding sites in MMP-9 expression after TNF- $\alpha$-treatment $(15,16)$.

Esculetin is an active compound derived from Artemisia scoparia (17), and is known to be a potent noncompetitive inhibitor of lipoxygenase (17). Esculetin also reportedly possesses a number of biological activities, such as 
anti-oxidant activity, suppression of xanthine oxidase activity, platelet aggregation, inhibition of human leukemia cell growth and anti-tumor activity (18-22). In addition, esculetin is known to inhibit VSMC prolifertion in vitro and neointima formation in vivo $(23,24)$. However, there is no evidence thus far of the possible effects of esculetin on migration and MMP-9 regulation in VSMC.

Data from the present study demonstrated the role of MMP-9 expression in the inhibition of VSMC migration and invasion.

\section{Materials and methods}

Materials. Esculetin was purchased from Sigma (St. Louis, MO, USA). TNF- $\alpha$ was obtained from R\&D Systems (Minneapolis, MN, USA). Polyclonal MMP-9 antibody was obtained from Chemicon International (Temecula, CA, USA).

Cell culture. VSMC were isolated from Sprague-Dawley rats. These explants were grown in DMEM containing $10 \%$ fetal bovine serum (FBS), $2 \mathrm{mM}$ glutamine, $50 \mu \mathrm{g} / \mathrm{ml}$ gentamycin and $50 \mu \mathrm{l} / \mathrm{ml}$ amphotericin-B at $37^{\circ} \mathrm{C}$ in a humidified $5 \% \mathrm{CO}_{2}$ atmosphere.

Invasion assay. VSMC were resuspended with TNF- $\alpha$ (100 ng/ $\mathrm{ml}$ ) alone or together with esculetin in $100 \mu \mathrm{l}$ of medium and placed in the upper chamber of the transwell plate. The cells were then incubated for $24 \mathrm{~h}$. Cells had to pass through a polycarbonate memebrane with a thin layer of ECM-like material and $8-\mu \mathrm{M}$ pores. The ability of VSMC to invade the ECM-like material was determined with a commercial cell invasion assay kit (Chemicon), as described previously (25).

Wound migration assay. VSMCs were plated on 6-well dishes and grown to $90 \%$ confluence in $2 \mathrm{ml}$ of growth medium. The cells were damaged using a 2-mm-wide tip, then treated with TNF- $\alpha(100 \mathrm{ng} / \mathrm{ml})$ alone or together with esculetin. The cells were allowed to migrate and photographs were captured through an inverted microscope (magnification, $\mathrm{x} 40$ ).

Immunoblotting assays. Growth-arrested VSMC were treated with TNF- $\alpha$ in the presence or absence of esculetin for specified time periods at $37^{\circ} \mathrm{C}$. Cell lysates were prepared and immunoblotting was performed as described previously (15).

Transient transfection. Each plasmid was transfected into VSMC using a Superfect reagent (Qiagen, Valencia, CA, USA) according to the manufacturer's instructions (15). Luciferase activity was measured using a luciferase assay system (Promega, Madison, WI, USA) according to the manufacturer's instructions. Firefly luciferase activity was standardized to $\beta$-galactosidase activity.

Zymography. The conditioned medium was electrophoresed in a polyacrylamide gel containing $1 \mathrm{mg} / \mathrm{ml}$ gelatin. The gel was then washed at room temperature for $2 \mathrm{~h}$ with $2.5 \%$ Triton $\mathrm{X}-100$, and then at $37^{\circ} \mathrm{C}$ overnight in a buffer containing $10 \mathrm{mM} \mathrm{CaCl}, 150 \mathrm{mM} \mathrm{NaCl}$ and $50 \mathrm{mM}$ Tris- $\mathrm{HCl}$ (pH 7.5). The gel was stained with $0.2 \%$ Coomassie blue and photographed on a light box. Proteolysis was detected as a white zone in a dark blue field.
Creation of MMP-9 promoter reporter construct. A $0.7-\mathrm{kb}$ segment in the 5'-flanking region of the human MMP-9 gene was amplified by PCR using specific primers from the human MMP-9 gene (Accession no. D10051): 5'-ACATTTGCCCGAGCTCCTGAAG (forward/SacI) and 5'-AGGGGCTGCCAGAAGCTTATGGT (reverse/HindIII). The pGL2-Basic vector containing a polyadenylation signal upstream of the luciferase gene was used to construct the expression vectors by subcloning PCR-amplified DNA of the MMP-9 promoter into the SacI/HindIII site of the pGL2-Basic vector (15). The size of the PCR products was confirmed by electrophoresis and DNA sequencing.

Nuclear extracts and electrophoretic mobility shift assay. Nuclear extracts were prepared essentially as described elsewhere (15). Cultured cells were collected by centrifugation, washed and suspended in a buffer containing $10 \mathrm{mM}$ Hepes (pH 7.9), 10 mM KCl, 0.1 mM EDTA, 0.1 mM EGTA, $1 \mathrm{mM}$ DTT and $0.5 \mathrm{mM}$ PMSF. After $15 \mathrm{~min}$ on ice, the cells were vortexed in the presence of $0.5 \%$ Nonidet NP-40. The nuclear pellet was then collected by centrifugation and extracted in a buffer containing $20 \mathrm{mM}$ Hepes (pH 7.9), 0.4 M NaCl, $1 \mathrm{mM}$ EDTA, $1 \mathrm{mM}$ EGTA, $1 \mathrm{mM}$ DTT and $1 \mathrm{mM}$ PMSF for $15 \mathrm{~min}$ at $4^{\circ} \mathrm{C}$.

The nuclear extract $(10-20 \mu \mathrm{g})$ was pre-incubated at $4^{\circ} \mathrm{C}$ for 30 min with a 100-fold excess of an unlabeled oligonucleotide spanning the -79 MMP-9 cis-element of interest. The sequences were as follows: AP-1, CTGACCCCTGAGTCAGCACTT; and

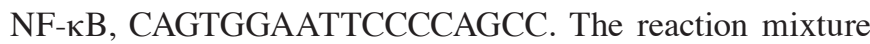
was then incubated at $4^{\circ} \mathrm{C}$ for $20 \mathrm{~min}$ in a buffer containing $25 \mathrm{mM}$ Hepes buffer (pH 7.9), $0.5 \mathrm{mM}$ EDTA, $0.5 \mathrm{mM}$ DTT, $0.05 \mathrm{M} \mathrm{NaCl}$ and $2.5 \%$ glycerol, with $2 \mu \mathrm{g}$ of poly $\mathrm{dI} / \mathrm{dC}$ and $5 \mathrm{fmol}\left(2 \times 10^{4} \mathrm{cpm}\right)$ of a Klenow end-labeled ( $\left.{ }^{32} \mathrm{P}-\mathrm{ATP}\right) 30$-mer oligonucleotide, which spans the DNA binding site in the MMP-9 promoter. The reaction mixture was electrophoresed at $4^{\circ} \mathrm{C}$ on a $6 \%$ polyacrylamide gel using a TBE ( $89 \mathrm{mM}$ Tris, 89 $\mathrm{mM}$ boric acid and $1 \mathrm{mM}$ EDTA) running buffer. The gel was rinsed with water, dried and exposed to X-ray film overnight.

Statistical analysis. When appropriate, data were expressed as the mean \pm SE. Data were analyzed by factorial ANOVA and Fisher's least significant difference test where appropriate. Statistical significance was set at $\mathrm{P}<0.05$.

\section{Results}

Esculetin suppressed TNF- $\alpha$-induced migration and invasion in VSMC. The effect of esculetin on TNF- $\alpha$-induced VSMC invasion and migration was first examined. As shown in Fig. 1A, treatment with TNF- $\alpha$ increased VSMC invasion through a Matrigel-coated membrane after $48 \mathrm{~h}$ of culture, compared to the untreated control. This TNF- $\alpha$-induced VSMC invasion was strongly inhibited by the addition of esculetin (12.5-25 $\mu \mathrm{g} / \mathrm{ml})$ in a dose-dependent manner (Fig. 1A). In addition, TNF- $\alpha$ treatment significantly induced the migration of VSMC, as determined using a wound migration assay (Fig. 1B). The migration induced by TNF- $\alpha$ was also attenuated by esculetin in a dose-dependent manner (Fig. 1B). However, under $25 \mu \mathrm{g} / \mathrm{ml}$ concentration conditions, esculetin did not affect cell viability (data not shown). 
A

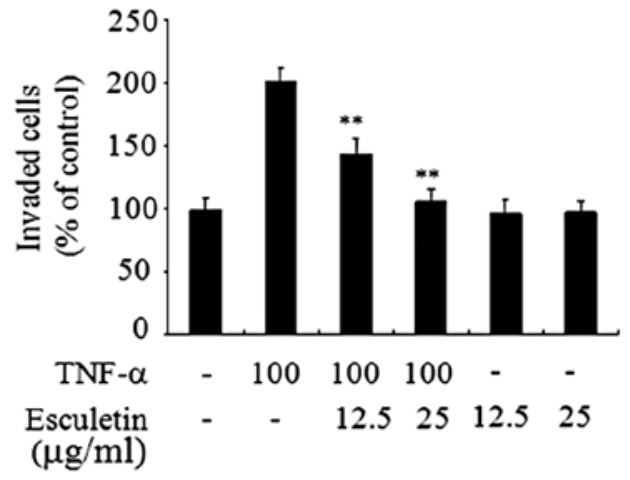

B

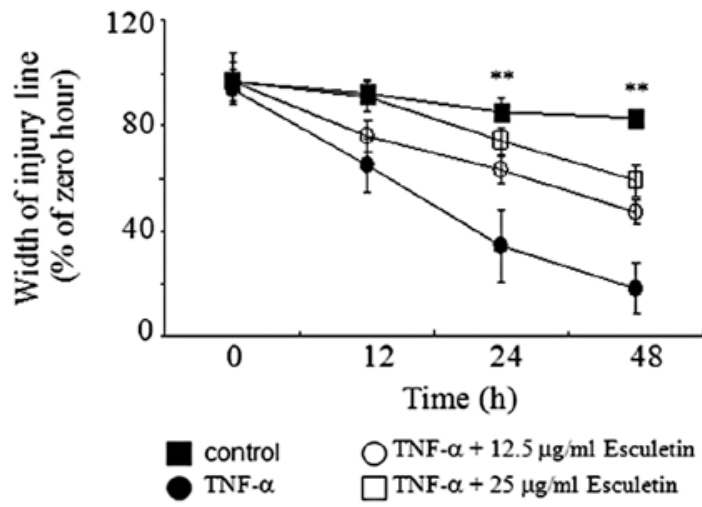

Figure 1. Effect of esculetin on inhibition of TNF- $\alpha$-induced invasion and migration in VSMC. (A) Cells seeded in serum-free medium were incubated on Matrigel-coated membranes of transwell plates and then exposed to 12.5 and $25 \mu \mathrm{g} / \mathrm{ml}$ esculetin for $40 \mathrm{~min}$, followed by the addition of TNF- $\alpha$ $(100 \mathrm{ng} / \mathrm{ml})$ for $48 \mathrm{~h}$. Results are expressed as the number of invaded cells relative to the untreated control, as determined from three independent experiments. ${ }^{* *} \mathrm{P}<0.05$ compared to TNF- $\alpha$ treatment. (B) Confluent cells in serum-free medium were incubated with 12.5 and $25 \mu \mathrm{g} / \mathrm{ml}$ esculetin for $40 \mathrm{~min}$, followed by the addition of TNF- $\alpha(100 \mathrm{ng} / \mathrm{ml})$. The widths of injury lines made in cells were measured at $0,12,24$ and $48 \mathrm{~h}$. Results are expressed as the widths of injury lines relative to the untreated control at $0 \mathrm{~h}$, as determined from three independent experiments. ${ }^{* *} \mathrm{P}<0.05$ compared to TNF- $\alpha$ treatment.

Esculetin inhibited TNF- $\alpha$-induced MMP-9 expression. To determine the effect of esculetin on TNF- $\alpha$-induced MMP-9 expression in VSMC, a gelatin zymographic assay was carried out. As shown in Fig. 2, treatment of cells with TNF- $\alpha$ induced MMP-9 expression in VSMC in the conditioned media. By contrast, the expression of MMP-2 was not affected by TNF- $\alpha$. Increased MMP-9 expression in response to TNF- $\alpha$ was attenuated by the addition of esculetin in a dose-dependent manner. Similar results were observed using immunoblotting. In addition, esculetin did not significantly affect the level of MMP-2 (Fig. 2A).

Esculetin inhibited MMP-9 promoter activity. To determine the exact mechanism of TNF- $\alpha$-induced MMP-9 expression at the transcriptional level, MMP-9 promoter activity was measured by transient transfection. TNF- $\alpha$-mediated MMP-9 promoter activation was performed in the absence or presence of esculetin using a pGL2-MMP-9WT plasmid in which the 710 bp human MMP-9 promoter segment was linked to the luciferase reporter gene (Fig. 3A). Treatment of cells transiently transfected with the pGL2-MMP-9WT plasmid

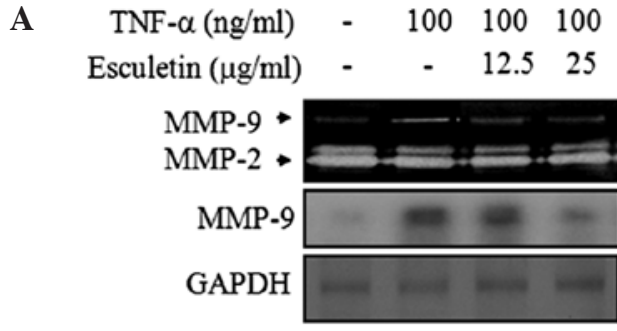

B

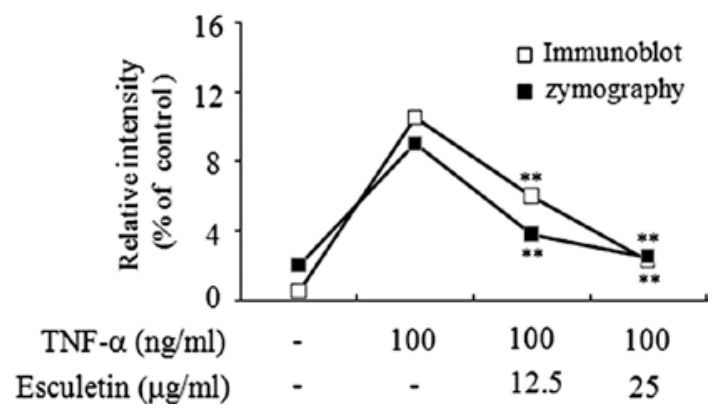

Figure 2. Effect of esculetin on TNF- $\alpha$-induced MMP-9 expression in VSMC. (A) Cells seeded in serum-free medium were incubated with TNF- $\alpha$ $(100 \mathrm{ng} / \mathrm{ml})$ for $24 \mathrm{~h}$ after $40 \mathrm{~min}$ of pre-treatment at the indicated concentrations $(\mu \mathrm{g} / \mathrm{ml})$ of esculetin, and then the conditioned media were analyzed zymographically for MMP activity. Similarly, an immunoblot analysis was conducted with antibodies specific for MMP-9. ${ }^{* *} \mathrm{P}<0.05$ compared to TNF- $\alpha$ treatment. (B) The expression of GAPDH was normalized by densitometric analysis for the relative intensity of MMP-9 expression. ${ }^{* *} \mathrm{P}<0.05$ compared to TNF- $\alpha$ treatment.
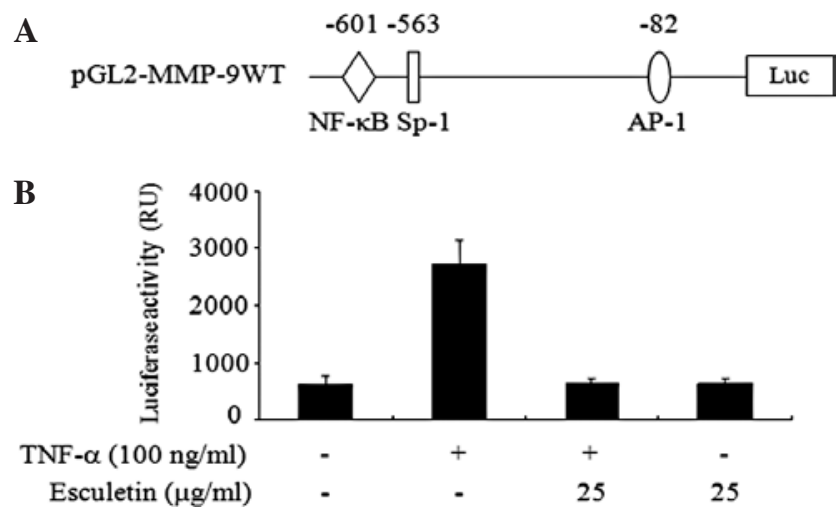

Figure 3. Inhibitory effect of esculetin on TNF- $\alpha$-induced MMP-9 promoter activity in VSMC. (A) Schematic presentation of the MMP-9 promoter, showing the cis-regulatory elements. (B) pGL2-MMP-9WT, which contains $710 \mathrm{bp}$ of the 5'-promoter region of the MMP-9 gene, was transfected into VSMC together with $\beta$-gal for the normalization of transfection efficiency. After $40 \mathrm{~min}$ of pre-treatment with or without the indicated concentrations of esculetin, the cells were incubated with TNF- $\alpha(100 \mathrm{ng} / \mathrm{ml})$ for an additional $24 \mathrm{~h}$. Luciferase activity was determined from cell lysates, as described in Materials and methods. ${ }^{* *} \mathrm{P}<0.05$ compared to TNF- $\alpha$ treatment.

with TNF- $\alpha$ markedly increased the reporter activity of this promoter construct (Fig. 3B). In addition, esculetin treatment caused a marked reduction in MMP-9 promoter activity induced by TNF- $\alpha$ (Fig. 3B).

Esculetin attenuated TNF- $\alpha$-induced MMP-9 promoter activity via suppression of $N F-\kappa B$ and $A P-1$ binding activity. 


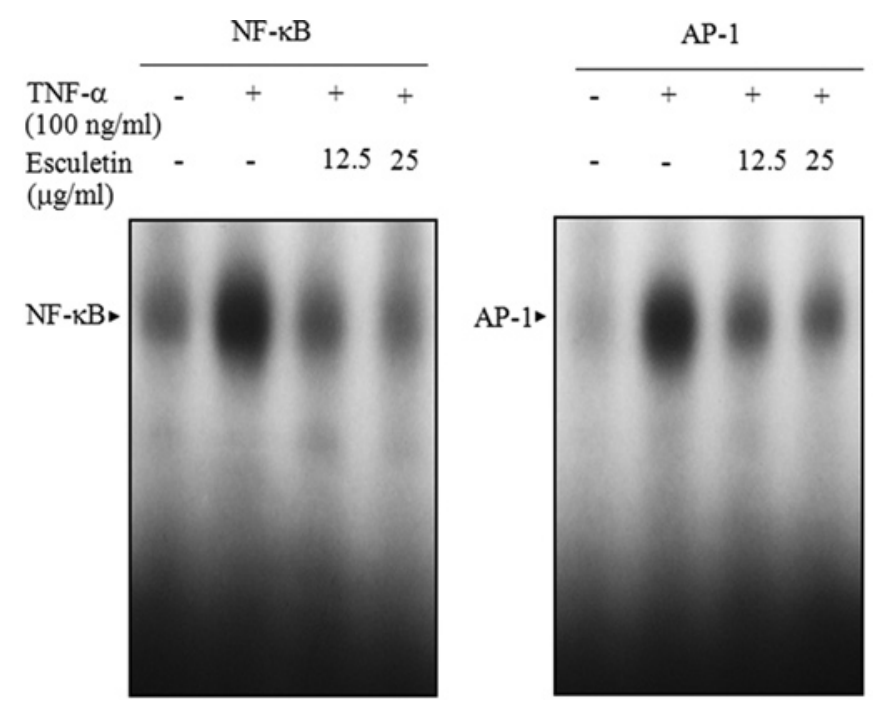

Figure 4. Dose-dependent inhibitory effect of esculetin on the DNA binding activity of NF- $\mathrm{KB}$ and AP-1 in TNF- $\alpha$-induced VSMC. Cells incubated in serum-free medium were pre-treated with the indicated concentrations of esculetin for $40 \mathrm{~min}$, followed by TNF- $\alpha$ (100 ng/ml) stimulation for $24 \mathrm{~h}$. After incubation, nuclear extracts from the cells were subjected to EMSA for activated $\mathrm{NF}-\kappa \mathrm{B}$ and $\mathrm{AP}-1$ using radiolabeled oligonucleotide probes.

Transcriptional binding motifs, such as NF- $\mathrm{B}, \mathrm{Sp}-1$ and AP-1, have been identified as transactivators of MMP-9 (Fig. 3A). Previous studies have demonstrated that TNF- $\alpha$ induces the activation of the MMP-9 promoter via NF- $\mathrm{KB}$ and AP-1 binding sites in VSMC $(15,16)$. To determine whether these two types of transcription factors are involved in the inhibition of MMP-9 expression induced by esculetin, the effect of esculetin on the DNA binding activity of $\mathrm{NF}-\kappa \mathrm{B}$ and AP-1 was examined using EMSA. As shown in Fig. 4, TNF- $\alpha$ significantly enhanced the binding activities of the $\mathrm{NF}-\kappa \mathrm{B}$ and AP-1 motifs. In addition, treatment of cells with esculetin inhibited TNF- $\alpha$-induced NF- $\kappa \mathrm{B}$ and AP-1 binding activity in VSMC (Fig. 4). These results demonstrate that the transcription factors $\mathrm{NF}-\kappa \mathrm{B}$ and AP-1 are likely to be involved in the repressive effect of esculetin on TNF- $\alpha$-induced MMP-9 expression.

\section{Discussion}

Esculetin reportedly has beneficial effects on cardiovascular disease in vitro and in vivo $(23,24)$. However, the exact molecular mechanisms of MMP-9 regulation in response to esculetin remain unknown. The purpose of the present study was to investigate the mechanism of MMP-9 regulation by esculetin in TNF- $\alpha$-treated VSMC.

First, the effect of esculetin on cell viability was examined using an MTT assay. The data showed that esculetin treatment ( $<25 \mu \mathrm{g} / \mathrm{ml}$ concentration) had no effect on cell death in TNF- $\alpha$-treated VSMC (data not shown). Next, the effects of esculetin on VSMC invasion and migration were investigated, because VSMC migration is a critical event in the development of neointima after vascular remodeling $(1,2)$. The inhibition of the invasion and migration of cells was observed following esculetin treatment in TNF- $\alpha$-treated VSMC in dose-dependent manner. MMPs play important roles in the degradation of the ECM to enable pathophysiological processes, such as vascular remodeling $(2,3)$. Among the various MMPs previously examined, it has generally been concluded that MMP-9 is one of the most important factors in VSMC physiology and vascular remodeling, and its expression can be stimulated by cytokine TNF- $\alpha(5-8,14,15)$. Elevated levels of MMP-9 were found to be integrally linked to the invasion and migration of VSMC (6-8). To understand how esculetin mediates the inhibition of VSMC migration and invasion in the presence of TNF- $\alpha$, we focused on MMP-9 expression. Treatment with esculetin inhibited TNF- $\alpha$-stimulated MMP-9 expression in a dose-dependent manner, as shown by zymographic and immunoblot analyses. The inhibition of MMP-9 expression induced by esculetin provides a convincing explanation for its suppression of VSMC migration and invasion. However, esculetin treatment did not affect MMP-2 expression. These results suggest that esculetin-mediated suppression of MMP-9 expression may cooperate with reduced VSMC migration and invasion via the degradation of the ECM.

The control of MMP-9 expression is largely regulated at the transcriptional stage (26). The present study found that esculetin significantly suppressed TNF- $\alpha$-induced transcriptional activity using MMP-9 promoter analysis. There are several cis-elements, NF- $\kappa \mathrm{B}, \mathrm{AP}-1$ and Sp-1 motifs, located at $-710 \mathrm{bp}$ in the promoter region of the MMP-9 gene $(15,16,27)$. Previous studies of the MMP-9 promoter found that pivotal $\mathrm{NF}-\kappa \mathrm{B}$ and AP-1 binding sites in TNF- $\alpha$-treated VSMC are essential $(15,16)$. Increasing evidence suggests a critical regulatory role of natural resources in the inhibition of MMP-9 expression in several cell lines (28-30). In the same vein, to further investigate the transcriptional regulation of esculetin in the suppression of MMP-9 expression in VSMC, the role of cis-elements in the esculetin-mediated inhibition of the MMP-9 gene in response to TNF- $\alpha$ was examined. The results showed that esculetin markedly inhibited $N F-\kappa B$ and AP-1 binding activity induced by TNF- $\alpha$. This suggests that esculetin inhibits MMP-9 expression through the suppression of NF- $\kappa \mathrm{B}$ and AP-1 binding activity in TNF- $\alpha$-treated VSMC. A previous study showed that esculetin suppressed MMP-1, MMP-3 and MMP-13 expression in interleukin-1 $\alpha$-treated chondrocyte cells (31). Another report demonstrated the effect of esculetin on the inhibition of MMP-1 and MMP-3 expression in rabbit joint cartilage explants (32). However, the present study is the first to show the regulatory effect of esculetin in the inhibition of MMP-9 expression via the decreased binding activity of the NF- $\kappa \mathrm{B}$ and AP-1 motifs.

In conclusion, the present data demonstrate that esculetin $(<25 \mu \mathrm{g} / \mathrm{ml})$ potently inhibits the migration and invasion of TNF- $\alpha$-treated VSMC without toxicity, by suppressing MMP-9 expression through the down-regulation of $\mathrm{NF}-\kappa \mathrm{B}$ and AP-1 binding activity. These findings suggest a potential therapeutic use of esculetin in the treatment of cardiovascular diseases and atherosclerosis.

\section{Acknowledgements}

This study was supported by the Basic Science Research Program through the National Research Foundation of Korea (NRF) funded by the Ministry of Education, Science and Technology (2010-0001736). 


\section{References}

1. Ross R: The pathogenesis of atherosclerosis: a perspective for the 1990s. Nature 362: 801-809, 1993.

2. Visse R and Nagase H: Matrix metalloproteinases and tissue inhibitors of metalloproteinases: structure, function, and biochemistry. Circ Res 92: 827-839, 2003.

3. Newby AC and Zaltsman AB: Molecular mechanisms in intimal hyperplasia. J Pathol 190: 300-309, 2000.

4. Zempo N, Kenagy RD, Au YP, Bendeck M, Clowes MM, Reidy MA and Clowes AW: Matrix metalloproteinases of vascular wall cells are increased in balloon-injured rat carotid artery. J Vasc Surg 20: 209-217, 1994.

5. Pauly RR, Passaniti A, Bilato C, Monticone R, Cheng L, Papadopoulos N, Gluzband YA, Smith L, Weinstein C, Lakatta EG and Crow MT: Migration of cultured vascular smooth muscle cells through a basement membrane barrier requires type IV collagenase activity and is inhibited by cellular differentiation. Circ Res 75: 41-54, 1994.

6. Bendeck MP, Zempo N, Clowes AW, Galardy RE and Reidy MA: Smooth muscle cell migration and matrix metalloproteinase expression after arterial injury in the rat. Circ Res 75: 539-545, 1994.

7. Cho A and Reidy MA: Matrix metalloproteinase-9 is necessary for the regulation of smooth muscle cell replication and migration after arterial injury. Circ Res 91: 845-851, 2002.

8. Galis ZS, Johnson C, Godin D, Magid R, Shipley JM, Senior RM and Ivan E: Targeted disruption of the matrix metalloproteinase- 9 gene impairs smooth muscle cell migration and geometrical arterial remodeling. Circ Res 91: 852-859, 2002.

9. Nabel EG and Nabel GJ: Prospects for gene therapy in cardiovascular diseases. In: Hypertension: Pathophysiology Diagnosis Management. 2nd edition. Laragh JH and Brenner BM (eds). Raven Press Ltd., New York, pp3137-3149, 1995.

10. Abedi $\mathrm{H}$ and Zachary I: Signalling mechanisms in the regulation of vascular cell migration. Cardiovasc Res 30: 544-556, 1995.

11. Jovinge S, Hultgardh-Nilsson A, Regnstrom $\mathbf{J}$ and Nilsson $\mathrm{J}$ : TNF- $\alpha$ activates smooth muscle cell migration in culture and is expressed in the balloon-injured rat aorta. Artherioscl Thromb Vasc Biol 17: 490-497, 1997.

12. Barath P, Fishbein MC, Cao J, Berenson J, Helfant RH and Forrester JS: Tumor necrosis factor gene expression in human vascular intimal smooth muscle cells detected by in situ hybridization. Am J Pathol 137: 503-509, 1990.

13. Rayment NB, Moss E, Faulkner L, Brickell PM, Davies MJ, Woolf $\mathrm{N}$ and Katz DR: Synthesis of TNF alpha and TGF beta mRNA in the different micro-environments within atheromatous plaques. Cardiovasc Res 32: 1123-1130, 1996.

14. Cho A, Graves J and Reidy MA: Mitogen-activated protein kinases mediate matrix metalloproteinase-9 expression in vascular smooth muscle cells. Arterioscler Thromb Vasc Biol 20: 2527-2532, 2000.

15. Moon SK, Cha BY and Kim CH: ERK1/2 mediates TNF-alphainduced matrix metalloproteinase-9 expression in human vascular smooth muscle cells via the regulation of NF-kappaB and AP-1: involvement of the ras dependent pathway. J Cell Physiol 198: 417-427, 2004

16. Bond M, Chase AJ, Baker AH and Newby AC: Inhibition of transcription factor NF-kappaB reduces matrix metalloproteinase- $1,-3$ and -9 production by vascular smooth muscle cells. Cardiovasc Res 50: 556-565, 2001.

17. Sekiya K, Okuda H and Arichi S: Selective inhibition of platelet lipoxygenase by esculetin. Biochim Biophys Acta 713: 68-72, 1982.
18. Lin WL, Wang CJ, Tsai YY, Liu CL, Hwang JM and Tseng TH: Inhibitory effect of esculetin on oxidative damage induced by t-butyl hydroperoxide in rat liver. Arch Toxicol 74: 467-472, 2000.

19. Egan D, O'Kennedy R, Moran E, Cox D, Prosser E and Thornes RD: The pharmacology, metabolism, analysis and applications of coumarin and coumarin-related compounds. Drug Metab Rev 22: 503-529, 1990.

20. Okada Y, Miyauchi Y, Suzuki K and Kobayashi T: Search for naturally occurring substances to prevent the complications of diabetes. II. Inhibitory effect of coumarin and flavonoid derivatives on bovine lens aldose reductase and rabbit platelet aggregation. Chem Pharm Bull 43: 1385-1387, 1995.

21. Wang CJ, Hsieh YJ, Chu CY, Lin YL and Tseng TH: Inhibition of cell cycle progression in human leukemia HL-60 cells by esculetin. Cancer Lett 183: 163-168, 2002.

22. Kok SH, Yeh CC, Chen ML and Kuo MY: Esculetin enhances TRAIL-induced apoptosis through DR5 upregulation in human oral cancer SAS cells. Oral Oncol 45: 1067-1072, 2009.

23. Huang HC, Lai MW, Wang HR, Chung YL, Hsieh LM and Chen CC: 1993. Antiproliferative effect of esculetin on vascular smooth muscle cells: possible roles of signal transduction pathways. Eur J Pharmacol 237: 39-44, 1993.

24. Pan SL, Huang YW, Guh JH, Chang YL, Peng CY and Teng CM: Esculetin inhibits Ras-mediated cell proliferation and attenuates vascular restenosis following angioplasty in rats. Biochem Pharmacol 65: 1897-1905, 2003.

25. Oak MH, El Bedoui J, Anglard P and Schini-Kerth VB: Red wine polyphenolic compounds strongly inhibit pro-matrix metalloproteinase-2 expression and its activation in response to thrombin via direct inhibition of membrane type 1-matrix metalloproteinase in vascular smooth muscle cells. Circulation 110: 1861-1867, 2004.

26. Westermarck J and Kähäri VM: Regulation of matrix metalloproteinase expression in tumor invasion. FASEB J 13: 781-792, 1999.

27. Sato H and Seiki M: Regulatory mechanism of $92 \mathrm{kDa}$ type IV collagenase gene expression which is associated with invasiveness of tumor cells. Oncogene 8: 395-405, 1993.

28. Dell'Agli M, Canavesi M, Galli G and Bellosta S: Dietary polyphenols and regulation of gelatinase expression and activity. Thromb Haemost 93: 751-760, 2005.

29. Stoclet JC, Chataigneau T, Ndiaye M, Oak MH, El Bedoui J, Chataigneau M and Schini-Kerth VB: Vascular protection by dietary polyphenols. Eur J Pharmacol 500: 299-313, 2004.

30. Bachmeier BE, Iancu CM, Jochum M and Nerlich AG: Matrix metalloproteinases in cancer: comparison of known and novel aspects of their inhibition as a therapeutic approach. Expert Rev Anticancer Ther 5: 149-163, 2005.

31. Elliott $S$, Rowan AD, Carrère S, Koshy $P$, Catterall JB and Cawston TE: Esculetin inhibits cartilage resorption induced by interleukin lalpha in combination with oncostatin M. Ann Rheum Dis 60: 158-165, 2001.

32. Yamada H, Watanabe K, Saito T, Hayashi H, Niitani Y, Kikuchi T, Ito A, Fujikawa K and Lohmander LS: Esculetin (dihydroxycoumarin) inhibits the production of matrix metalloproteinases in cartilage explants, and oral administration of its prodrug, CPA-926, suppresses cartilage destruction in rabbit experimental osteoarthritis. J Rheumatol 26: 654-662, 1999. 